Dept. of Food Hygiene,

Faculty of Veterinary Medicine, Assiut University.

\title{
DETECTION OF COXIELLA BURNETII IN BOVINE MILK SAMPLES USING POLYMERASE CHAIN REACTION \\ (With One Figure)
}

By

W.F. AMIN and S.O. AHMED*

*: Dept. of Animal Hygiene,

Faculty of Veterinary Medicine, Assiut University.

(Received at 15/8/2009)

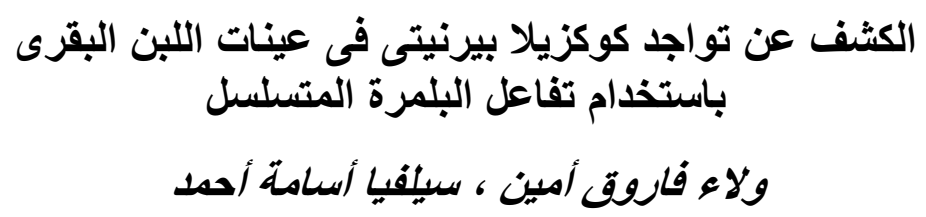

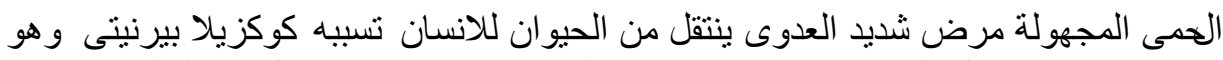

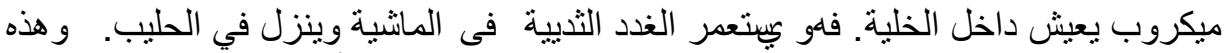

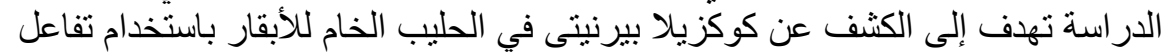

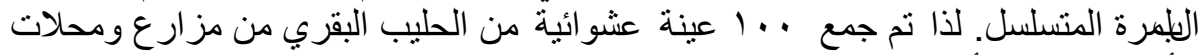

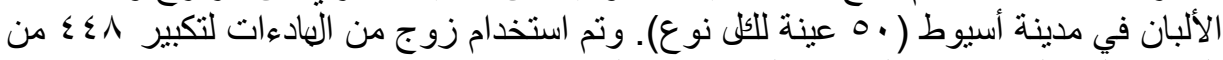

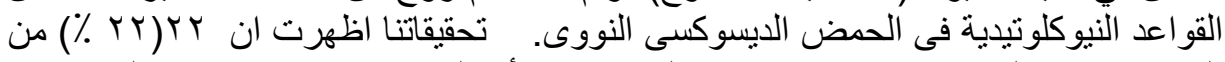

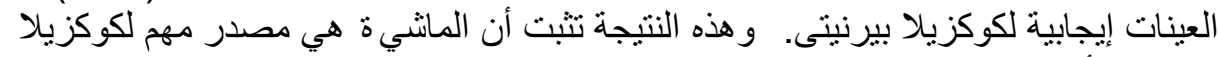

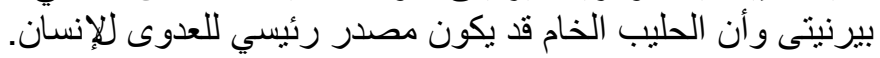

\section{SUMMARY}

Q fever is a highly contagious zoonotic disease caused by the intracellular pathogen Coxiella burnetii. It colonizes mammary glands of cattle and is shed in milk. This study was aimed to detect C.burnetii in raw bovine milk using Polymerase Chain Reaction (PCR). A total of 100 random bovine milk samples were collected from both dairy farms and shops in Assiut City, Egypt (50 samples each). A pair of primers served to amplify a targeted 448-bp fragment of genomic DNA. Our investigation showed that $22(22 \%)$ of samples were found to be positive for $C$. burnetii. This result proves that cattle are an important reservoir for C.burnetii organism and raw milk may be a main source of infection to humans.

Key words: Coxiella burnetii, milk, PCR. 


\section{INTRODUCTION}

Query (Q) fever, due to Coxiella burnetii, is a ubiquitous zoonosis with a worldwide distribution except New Zealand. It was first described by Derrick in 1935 in Queensland, Australia, during an outbreak of a febrile illness among abattoir workers (Derrick, 1937).

C. burnetii is an obligate intracellular, has a gram negative cell wall structure. Q-fever affects different animal species and humans. Clinical presentation in humans ranges from mild flu-like symptoms to, sometimes, severe atypical pneumonia and hepatitis (Raoult et al., 2005). Convalescence can be slow and endocarditis is the most frequent and serious manifestation of chronic Q-fever (Gami et al., 2004). In addition, the C.burnetii infection can lead to abortions, stillbirth, or premature deliveries in pregnant women (Raoult and Marrie, 1995). In animals, primarily cattle, sheep, and goats, C. burnetii can cause abortion and infertility as it localizes in the female reproductive system. High doses of $C$. burnetii have been found in conception products of infected animals. The organism is shed in the urine, faeces and milk of infected animals. In general, infected animals remain asymptomatic (Maurin and Raoult, 1999).

This agent is very resistant to environmental influences, and even a single infective particle can initiate an infection in the animal model (Ormsbee et al., 1978).

From the literature, C. burnetii is shed by ruminants in milk (Adesiyun et al., 1985; Durand, 1993; Willems et al., 1994; Lorenz et al., 1998 and Berri et al., 2000).

Oral transmission by ingestion of contaminated raw milk or dairy products could lead to seroconversion and perhaps, in a few cases, to $\mathrm{Q}$ fever (Benson et al., 1963 and Fishbein and Raoult, 1992).

Isolation of the $\mathrm{Q}$ fever agent by laboratory workers is difficult because the agent has a high infectivity rate, it is cumbersome in in vitro culture conditions, and handling it requires rigorous compliance requirements (Hoover et al., 1992). Moreover, isolation of C. burnetii requires several days (and sometimes weeks) and is time-consuming (Stein and Raoult, 1992b), it also requires confined bio safety level 3 laboratories due to the zoonotic nature of the microorganism (Field et al., 2000).

Serological tests (complement fixation, immunofluorescence, enzyme linked immunosorbent assays) which are classically used in routine diagnosis and large-scale epidemiological studies to detect antibody-carriers against $C$. burnetii. Since antibodies often persist for 
years after the illness, discrimination between current and past infections is difficult (Maurin and Raoult, 1999). Furthermore, a lack of sensitivity in these techniques has already been reported (Hassig and Lubsen, 1998 and Berri et al., 2001) considering the low level of shedding and the minimum infectious dose of $C$. burnetii.

In the last few years, conventional polymerase chain reaction (PCR) has become a very useful method for the detection of $C$. burnetii DNA in milk samples taken from dairy cattle (Willems et al., 1994 and Lorenz et al., 1998). The application of the polymerase chain reaction (PCR), which uses specific oligonucleotide primers and Taq DNA polymerase to synthesize copious quantities of DNA from a single template (Saiki et al., 1988), provides a valuable new approach in view of its sensitivity and broad applicability. The PCR assay has proved to be highly specific and sensitive for the laboratory diagnosis of C. burnetii infections, as it detects even very few copies of a specific DNA sequence. It detects $C$. burnetii in samples immediately, unlike serologic assays that detect antibodies that could have been introduced months earlier (Hoover et al., 1992). The availability of primers derived from genes specific to $C$. burnetii has allowed a simple and reliable method for the detection of this bacterium (Stein and Raoult, 1992a).

Our study was to detect $C$. burnetii in bovine raw milk available for consumers in Assiut City, Egypt using PCR for assessment of its incidence.

\section{MATERIALS and METHODS}

\section{The study samples:}

One hundred random raw milk samples from dairy farms and shops in Assiut city, Egypt (50 samples each), were collected under aseptic conditions in sterile containers and stored at $4{ }^{\circ} \mathrm{C}$ during transport, without delay to the laboratory for investigation.

DNA Extraction (According to Rodolakis et al., 2007)

DNA was extracted using the QIAmp DNA mini kit ${ }^{\circledR}$ (Qiagen S.A., Courtaboeuf Cedex, France) according to the manufacturer's instructions. Extraction was performed directly from $400 \mu \mathrm{L}$ of raw milk.

\section{PCR Primers:}

Primers amplifying a 448 bp product of the transposase gene of C. burnetii (IS1111);

Trans-f $\left(5^{\prime} \square\right.$ TTAAGGTGGGCTGCGTGGTGATGG-3') and trans-r (5'- GCTTCGTCCCGGTTCAACAATTCG-3'). 
PCR Method (According to Panning et al., 2008)

The PCR technique was performed in a thermocycler (HyBaidOmniGene, U.K.) in a total reaction volume of $50 \mu \mathrm{l}$ with $25 \mu 12 \times P C R$ Master Mix (Bioron, Germany), $0.5 \mu \mathrm{M}$ of each primer, $2 \mu \mathrm{l}$ of total DNA. Thermal cycling involved $94^{\circ} \mathrm{C}$ for $9 \mathrm{~min}$, followed by 5 cycles of $94^{\circ} \mathrm{C} 30 \mathrm{~s}, 75^{\circ} \mathrm{C}$ to $67^{\circ} \mathrm{C} 30 \mathrm{~s}$ with $2^{\circ} \mathrm{C}$ decrements per cycle, $77^{\circ} \mathrm{C} 30 \mathrm{~s}$; and 37 cycles of $94^{\circ} \mathrm{C} 30 \mathrm{~s}, 65^{\circ} \mathrm{C} 30 \mathrm{~s}, 77^{\circ} \mathrm{C} 30 \mathrm{~s}$ with a final elongation step at $77^{\circ} \mathrm{C} 2 \mathrm{~min}$.

\section{Detection of the amplification product}

Samples $(10 \mu \mathrm{l})$ were removed from the reaction mixture, examined by electrophoresis in $2 \%$ agarose gel, stained with ethidium bromide under UV illumination.

The DNA extraction, PCR assay and detection of amplification product were done in the department of Microbiology, Faculty of Medicine, Assiut University, Egypt.

\section{RESULTS}

A total of $22(22 \%)$ samples were found PCR positive for Coxiella burnetii from the examined 100 random raw bovine milk samples. Amplification revealed a band at $448 \mathrm{bp}$.

Some PCR amplification products are shown in Figure 1.

Fig. 1: PCR technique for Coxiella burnetii (specific amplification of the 448-bp fragment from the total DNA of Coxiella burnetii.

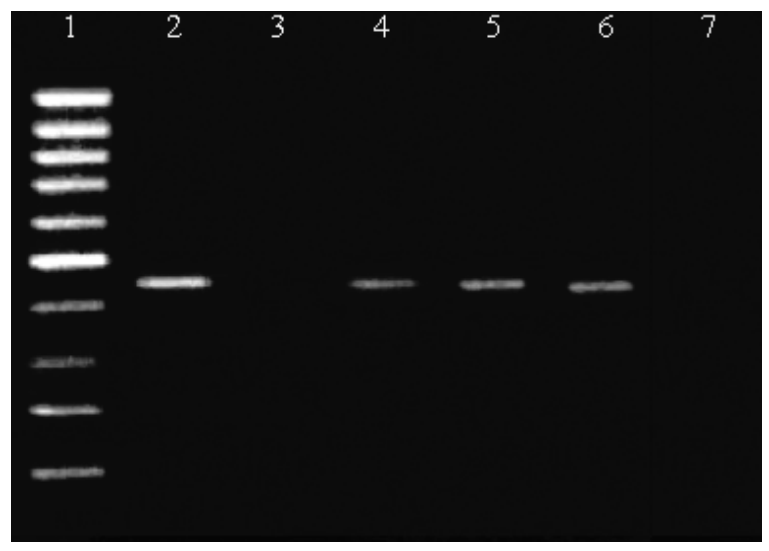

Lane 1: 100-bp DNA ladder, (Axygen Bioscience) was used as a molecular weight marker.

Lanes 2, 4, 5, 6: positive raw milk samples indicate $C$. burnetii.

Lane 7: negative control without DNA. 


\section{DISCUSSION}

Although described 70 years ago, Q fever is still a poorly understood disease (Raoult, 1996 and Mege et al., 1997). Its exact prevalence is unknown; it is likely that the number of cases of Q fever is underestimated.

Coxiella burnetii is a highly infectious zoonotic disease; only one organism is required to produce infection under experimental conditions (Ormsbee et al., 1978). Likewise, C. burnetii is currently considered a potential warfare agent and is classified as a category B biological agent by the Centre for Diseases Control and Prevention (Franz et al., 1997).

Because raw milk is used commercially in Egypt, milk was examined because of public health concerns. The raw milk of infected cows is an important material for detecting $C$. burnetii and diagnosing bovine coxiellosis (Bell et al., 1949 and Stoenner, 1951).

C. burnetii has already been detected using different PCR methods in the milk samples of infected dairy cows (Willems et al., 1994; Muramatsu et al., 1996 and Lorenz et al., 1998). The previously reported percentages of $C$. burnetii seropositive cows that shed the agent through their milk range from 8.3 to $90 \%$ (Benson et al., 1963 and Durand, 1993).

This study revealed that $22 \%$ of the samples were PCR positive for Coxiella burnetii. C. burnetii was detected in a very higher incidence than this study by Kim et al. (2005) who detected it in $94.3 \%$ in bulk tank milk in USA. While, it was detected in a lower incidence by Ho et al. (1995) who detected it from raw milk in Japan (16.8\%). Meanwhile, Guatteo et al. (2006) detected C. burnetii in a nearly similar incidence to this study (24.4\%) in milk samples. This variation in recovery rate may be attributed to differences in geographic distribution and to the different methods of detection.

On comparison of the incidence of $C$. burnetii in milk samples coming from farms to those coming from dairy shops, there was no significant difference between them.

Control measures of $C$. burnetii infection in infected herds could be done by isolating infected pregnant animals and burning or burying the reproductive membranes and placenta can decrease transmission. The occurrence of $C$. burnetii in the environment can also be reduced by regular cleaning, particularly of areas where animals give birth. Cleaning should be followed by disinfection with $10 \%$ bleach. Antibiotics may be given prophylactically (e.g. tetracyclines) before animals give birth 
(Maurin and Raoult, 1999). However, owing to the existence of apparently healthy (i.e. non-aborted) cows shedding Coxiella burnetii in various specimens, as well as, the high infectivity of Coxiella (Heinzen et al., 1999), the exposed workers (especially farmers, veterinarians and abattoir workers) should be informed about the risks and clinical signs of human $\mathrm{Q}$ fever, in order to allow for early detection of the disease.

As for the public health concerns of infection with $C$. burnetti through milk and since high temperature pasteurization destroys the organism, all milk to be consumed should be pasteurized.

\section{REFERENCES}

Adesiyun, A.A.; Jagun, A.G.; Kwaga, J.K. and Tekdek, L.B. (1985): Shedding of Coxiella burnetii in milk by Nigerian dairy and dual purposes cows. Int. J. Zoonoses, 12: 1-5.

Bell, E.J.; Parker, R.R. and Stoenner, H.G. (1949): Q feverexperimental Q fever in cattle. Am. J. Public Health, 39: 478- 484.

Benson, W.W.; Brock, D.W. and Mather, J. (1963): Serologic analysis of a penitentiary group using raw milk from a $\mathrm{Q}$ fever infected herd. Public Health Rep., 78: 707-710.

Berri, M.; Laroucau, K. and Rodolakis, A. (2000): The detection of Coxiella burnetii from ovine genital swabs, milk and fecal samples by the use of a single touchdown polymerase chain reaction. Vet. Microbiol., 72: 285-293.

Berri, M.; Souriau, A.; Crosby, M.; Crochet, D.; Lechopier, P. and Rodolakis, A. (2001): Relationships between the shedding of Coxiella burnetii, clinical signs and serological responses of 34 sheep. Vet. Rec., 148: 502-505.

Derrick, E.H. (1937): Q-fever, a new fever entity: clinical features, diagnosis and laboratory investigation. Med. J. Aust., 2: 281-299.

Durand, M.P. (1993): L'excre'tion lacte'e et placentaire de Coxiella burnetii, agent de la Fie`vre Q, chez la vache. Importance et pre'vention. Bull. Acad. Natl. Med. (Paris), 6: 935-946. (Cited after Guatteo et al., 2006). 
Field, P.R.; Mitchell, J.L.; Santiago, A.; Dickeson, D.J.; Chan, S.W.; Ho, D.W.; Murphy, A.M.; Cuzzubbo, A.J. and Devine, P.L. (2000): Comparison of a commercial enzyme-linked immunosorbent assay with immunofluorescence and complement fixation tests for detection of Coxiella burnetii (Q fever) immunoglobulin M. J. Clin. Microbiol., 38: 1645-1647.

Fishbein, D.B. and Raoult, D. (1992): A cluster of Coxiella burnetii infections associated with exposure to vaccinated goats and their unpasteurized dairy products. Am. J. Trop. Med. Hyg., 47: 35- 40.

Franz, D.R.; Jahrling, P.B.; Friedlander, A.M.; McClain, D.J.; Hoover, D.L. and Bryne, W.R. (1997): Clinical recognition and management of patients exposed to biological warfare agents. JAMA, 278: 399-411.

Gami, A.S.; Antonios, V.S.; Thompson, R.L.; Chaliki, H.P. and Ammash, N.M. (2004): Q fever endocarditis in the United States. Mayo Clin. Proc., 79: 253-257.

Guatteo, R.; Beaudeau, F.; Berri, M.; Rodolakis, A.; Joly, A. and Seegers, H. (2006): Shedding routes of Coxiella burnetii in dairy cows: implications for detection and control. Vet. Res., 37: 827-833.

Hassig, M. and Lubsen, J. (1998): Relationship between abortions and seroprevalences to selected infectious agents in dairy cows. J. Vet. Med. B, 45: 435-441.

Heinzen, R.A.; Hackstadt, T. and Samuel, J.E. (1999): Developmental biology of Coxiella burnetii. Trends Microbiol., 7: 149-154.

Ho, T.; Htwe, K.K.; Yamasaki, N.; Zhang, G.Q.; Ogawa, M.; Yamaguchi, T.; Fukushi, H. and Hirai, K. (1995): Isolation of Coxiella burnetii from dairy cattle and ticks, and some characteristics of the isolates in Japan. J. Microbiol. Immunol., 39 (9): 663-671.

Hoover, T.A.; Vodkin, M.H. and Williams, J.C. (1992): A Coxiella burnetii repeated DNA element resembling a bacterial insertion sequence. J. Bacteriol., 174: 5540-5548.

Kim, S.G.; Kim, E.H.; Lafferty, C.J. and Dubovi, E. (2005): Coxiella burnetii in bulk tank milk samples, United States. Emerging Infectious Diseases -www.cdc.gov/eid- 11 (4): 619-621. 
Lorenz, H.; Jager, C.; Willems, H. and Baljer, G. (1998): PCR detection of Coxiella burnetii from different clinical specimens, especially bovine milk, on the basis of DNA preparation with a silica matrix. Appl. Environ. Microbiol., 64: 4234-4237.

Maurin, M. and Raoult, D. (1999): Q fever. Clin. Microbiol. Rev., 518-553.

Mege, J.L.; Maurin, M.; Capo, C. and Raoult, D. (1997): Coxiella burnetii: the "query" fever bacterium a model of immune subversion by a strictly intracellular microorganism. FEMS Microbiol. Rev., 19: 209-217.

Muramatsu, Y.; Maruyama, M.; Yanase, T.; Ueno, H. and Morita, C. (1996): Improved method for preparation of samples for the polymerase chain reaction for detection of Coxiella burnetii in milk using immunomagnetic separation. Vet. Microbiol., 51: 179-185.

Ormsbee, R.A.; Peacock, M.G.; Gerloff, R.; Tallent, G. and Wike, D. (1978): Limits of rickettsial infectivity. Infect. Immun., 19: 239-245.

Panning, M.; Kilwinski, J.; Greiner-Fischer, S.; Peters, M.; Kramme, S.; Frangoulidis, D.; Meyer, H.; Henning, K. and Drosten, C. (2008): High throughput detection of Coxiella burnetii by realtime PCR with internal control system and automated DNA preparation. BMC Microbiology, 8: 77-85.

Raoult, D. (1996): Q fever: still a query after all these years. J. Med. Microbiol., 44:77-78.

Raoult, D. and Marrie, T. (1995): Q fever. Clin. Infect. Dis., 20: 489495.

Raoult, D.; Marrie, T. and Mege, J. (2005): Natural history and pathophysiology of Q fever. Lancet Infect. Dis., 5: 219-226.

Rodolakis, A.; Berri, M.; He'chard, C.; Caudron, C.; Souriau, A.; Bodier, C.; Blanchard, B.; Camuset, P.; Devillechaise, P.; Natorp, J.C.; Vadet, J.P. and Arricau-Bouvery, N. (2007): Comparison of Coxiella burnetii Shedding in Milk of Dairy Bovine, Caprine, and Ovine Herds. J. Dairy Sci., 90: 5352-5360.

Saiki, R.K.; Gelfand, D.H.; Stoffel, S.; Scharf, S.J.; Higuchi, R.; Horn, G.T.; Mullis, K.B. and Erlich, H.A. (1988): Primer directed enzymatic amplification of DNA with a thermostable DNA polymerase. Science, 293: 487-491. 
Stein, A. and Raoult, D. (1992a): Detection of Coxiella burnetii by DNA amplification using polymerase chain reaction. J. Clin. Microbiol., 30: 2462- 2466.

Stein, A. and Raoult, D. (1992b): Phenotypic and genotypic heterogeneity of 8 new human Coxiella bumetii isolates. Acta Virol. (Prague), 3: 7-12.

Stoenner, H.G. (1951): Experimental Q fever in cattle-epizootiologic aspects. J. Am. Vet. Assoc., 118: 170-174.

Willems, H.; Thiele, D.; Frölich-Ritter, R. and Krauss, H. (1994): Detection of Coxiella burnetii in cow's milk using the polymerase chain reaction (PCR). J. Vet. Med. B, 41: 580-587. 